\begin{tabular}{|c|} 
ISSN = 1980-993X - doi:10.4136/1980-993X \\
www.agro.unitau.br/ambi-agua \\
E-mail: ambi-agua@agro.unitau.br \\
Tel.: (12) 3625-4116
\end{tabular}

\title{
Controle qualitativo e quantitativo do escoamento pluvial urbano com bacias de detenção \\ (doi:10.4136/ambi-agua.36)
}

\section{Néstor Aldo Campana; Ricardo Silveira Bernardes; Jolival Antonio da Silva Jr.}

\author{
Departamento de Engenharia Civil e Ambiental - ENC \\ Faculdade de Tecnologia - FT. Universidade de Brasília - UnB \\ Campus Universitário Darcy Ribeiro - Asa Norte - Brasília/DF - CEP 70.910-900 \\ E-mail: mnestor@unb.br; ricardo@unb.br; jolivaljr@gmail.com
}

\section{RESUMO}

As cheias urbanas são responsáveis por transtornos que vão desde pequenos empoçamentos a enormes prejuízos materiais e à saúde humana. Com o intuito de minimizar o efeito das enchentes em áreas urbanas, várias metodologias vêm sendo estudadas. Dentre elas, as bacias de detenção e retenção são bastante utilizadas em áreas com urbanização consolidada. Neste estudo apresenta-se uma análise da eficiência de duas bacias de detenção uma seca e outra alagada - no controle de inundações abordando os aspectos quantitativo e qualitativo do escoamento proveniente da rede de drenagem pluvial da cidade de Brasília DF, Brasil. O afluente para as bacias de detenção é proveniente de sistema convencional de drenagem urbana com $4,75 \mathrm{~km}^{2}$ (bacia seca) e $6,12 \mathrm{~km}^{2}$ (bacia alagada) de área de contribuição. Os resultados mostraram a eficiência dos dispositivos monitorados na redução das vazões de pico, redução média observada de 62,6\% e 74\%, para a bacia de detenção seca e alagada, respectivamente. Além disso, essas estruturas reduzem as concentrações de alguns poluentes encontrados nas águas pluviais despejadas nas referidas bacias de detenção, com valores médios de remoção variando na faixa de 1 a 3\% para DBO até a faixa de 41 a $74 \%$ para Sólidos Suspensos.

Palavras-chave: detenção; cheias; drenagem urbana.

\section{Qualitative and quantitative control of the urban runoff with detention basins}

\begin{abstract}
Floods in urban areas are responsible for impacts that go from puddles formation to environmental and social disasters. Looking for alternatives to minimize the effects of floods in urban areas, some methodologies have been studied and applied, such as the use of detention basin in high consolidated urban areas. This study analyses the efficiency on flood control of two detention basins, a dry and a wet one. The study approaches both quantitative and qualitative aspects related to runoff from an urban area of Brasilia city, federal district of Brazil. The affluent caught by the detention basins is related to a conventional urban drainage system with a $4.75 \mathrm{~km}^{2}$ (dry basin) and $6.12 \mathrm{~km}^{2}$ (wet basin) contribution area. The results showed that the basins can reduce the peak income flow significantly (averaged $62.6 \%$ and $74 \%$ peak flow reduction, for dry and wet basin, respectively) and has positive impact over pollution control, with an average reduction of 1 to $3 \%$ for BOD and up to 41 to $74 \%$ for Suspended Solids.
\end{abstract}

Keywords: Detention basin; wet pond; urban runoff. 


\section{INTRODUÇÃO}

Com o aumento das áreas impermeáveis nas cidades, o aumento progressivo de eventos de inundações e a ineficiência dos dispositivos inseridos para a condução do escoamento proveniente das chuvas em áreas urbanas têm mostrado ao meio técnico um cenário preocupante. Desde essa constatação, dia-a-dia têm-se buscado novas alternativas para o controle das cheias em áreas urbanas.

Os incrementos nas vazões decorrentes das chuvas em áreas urbanas vêm sendo objeto de estudo de inúmeras pesquisas. Num primeiro momento, a quantificação dos acréscimos observados por simulação se tornou uma ferramenta de grande utilidade para a adoção de medidas que auxiliem no controle desses acréscimos evitando, assim, a ocorrência de inundações. No entanto, é de suma importância a validação dos resultados obtidos com observações in loco.

Uma outra preocupação diz respeito ao aspecto qualitativo das águas pluviais. Quando da ocorrência de eventos de inundação, a constatação da contaminação da população sujeita ao contato com as águas de chuva também mostrou claramente a necessidade de se investigar os tipos de compostos carreados pelas águas pluviais nas ruas e córregos urbanos. Levando-se em conta o sistema separador absoluto adotado pela grande maioria das cidades brasileiras, a detecção de despejos domésticos clandestinos na rede de drenagem obriga a administração local a fazer o tratamento antes da descarga nos rios, das águas pluviais urbanas.

Uma das medidas mais difundidas para o controle de inundações no período higienista foi a canalização de córregos urbanos, que com o tempo, mostrou-se ineficiente no sentido de conter as cheias na sua totalidade, pois esse dispositivo apenas transfere os efeitos das cheias urbanas para jusante, conforme cita Canholi (2005).

Conforme Silva (2006), desde o início da década dos anos 90 surgiu no Brasil um novo paradigma para a drenagem urbana o qual abandona o conceito tradicional de drenagem que consistia em retirar o excedente superficial o mais rápido possível da bacia hidrográfica, para se adotar um modelo compensatório que não permite a propagação do excedente superficial para jusante, mas, sim, a permanência deste na bacia hidrográfica, obviamente em local apropriado para não gerar interferências à população.

A partir desse momento são incorporadas ao sistema de drenagem urbana as denominadas medidas compensatórias que visam ao armazenamento temporário do excedente superficial e/ou a infiltração dele, ou parte, no solo. Esse tipo de solução é conhecido também como medida estrutural, uma vez que envolve a construção de uma obra física.

Diversos pesquisadores tais como Campana e Tucci (2001), Bertoni (2004), Chocat et al. (2004), Jones et al. (2006), entre outros, citam que dentre as medidas compensatórias mais amplamente difundidas, destacam-se os dispositivos de infiltração tais como bacia e valas de infiltração e percolação, que reduzem o volume do escoamento superficial e possibilitam a recarga do lençol freático e os dispositivos de detenção e retenção tais como reservatórios abertos ou enterrados, impermeáveis ou não, que têm por objetivo o controle da vazão lançada nas galerias de águas pluviais e corpos d'água receptores.

Em áreas de ocupação muito densa, que dificultam a utilização de medidas que favorecem a infiltração que demandam espaços relativamente grandes, uma medida bastante difundida é a utilização de reservatórios ou bacias de detenção e retenção. No tocante ao aspecto hidráulico dos reservatórios, pelos estudos já desenvolvidos por simulação matemática, pode-se concluir que estes se apresentam como alternativa viável do ponto de vista da redução dos picos dos hidrogramas de cheia. 
As medidas para o controle de cheias podem assumir características preventivas ou corretivas conforme a etapa de execução delas. As medidas não estruturais, pela sua essência, possuem um caráter preventivo tanto no aspecto quantitativo quanto no aspecto qualitativo.

A convivência com a inundação por meio da utilização de sistemas de alerta e seguro contra inundação e o respeito ao zoneamento de áreas de inundação como uma forma de restringir e organizar a ocupação urbana são exemplos de medidas não estruturais. De acordo com Baptista et al. (2005), as medidas não estruturais incluem, também, o planejamento da deposição de resíduos perigosos tais como substâncias tóxicas, restos de tinta, solventes e pesticidas, os programas de prevenção e controle da erosão, varrição de ruas e disposição adequada do lixo urbano e o controle de pontos potencialmente poluidores.

As medidas estruturais, a princípio utilizadas para o controle quantitativo, também têm efeito sobre a concentração de poluentes carreados pelas águas pluviais, conforme citam Mays e Pe (2001) e Urban Drainage and Flood Control District (1991). A Tabela 1 apresenta alguns resultados divulgados pela literatura sobre a eficiência de medidas estruturais na remoção de poluentes.

Tabela 1. Eficiência das medidas estruturais na melhoria da qualidade da água.

\begin{tabular}{l|c|c|c|c|c}
\hline \multirow{2}{*}{\multicolumn{1}{c|}{ Alternativa de controle }} & \multicolumn{5}{c}{ Porcentagem de remoção } \\
\cline { 2 - 6 } & $\begin{array}{c}\text { Sólido em } \\
\text { suspensão }\end{array}$ & $\begin{array}{c}\text { Fósforo } \\
\text { Total }\end{array}$ & $\begin{array}{c}\text { Nitrogênio } \\
\text { Total }\end{array}$ & Zinco & \multirow{2}{*}{ Bactéria } \\
\hline Minimização de áreas conectadas & n.d. & n.d. & n.d. & n.d. & n.d. \\
Faixas gramadas & $10-20$ & $0-10$ & $0-10$ & $0-10$ & n.d. \\
Valetas gramadas & $20-40$ & $0-15$ & $0-15$ & $0-20$ & n.d. \\
Bacias de detenção secas & $50-70$ & $10-20$ & $10-20$ & $30-60$ & $50-90$ \\
Bacias de detenção alagadas & $60-95$ & $0-80$ & $0-80$ & $0-70$ & n.d. \\
Alagadiços & 40 & $9-60$ & $9-60$ & 60 & n.d. \\
Pavimento poroso & $80-95$ & 65 & 65 & 99 & n.d. \\
\hline
\end{tabular}

n.d.: informação não disponível

Fonte: Urban Drainage and Flood Control District (1992 apud PMSP, 1999).

Um aspecto relevante a ser destacado é a diferença entre os sistemas de distribuição de água potável e coleta de esgoto, e o sistema de drenagem urbana. Este último funciona apenas no período chuvoso (uns poucos meses durante o ano) e o resto do tempo fica ocioso; enquanto os outros dois sistemas funcionam os 365 dias do ano.

Esse comportamento característico do sistema de drenagem urbana o torna uma infraestrutura relativamente cara se comparada a seu uso. Então, com o intuito de melhorar a relação custo-benefício surge uma nova tendência no desenvolvimento de sistemas de drenagem urbana que é a incorporação de funções múltiplas a essa infra-estrutura.

Especificamente com relação às bacias de detenção, Walesh (1989) cita que a incorporação de funções múltiplas fica evidente ao se analisar a evolução mundial de utilização das obras de detenção em centros urbanos. Conforme mostra a Figura 1, distinguem-se pelo menos quatro fases: numa primeira fase, as obras de detenção visavam apenas ao controle quantitativo do escoamento; numa fase posterior, além da função específica do controlo do escoamento superficial, foram concebidas e integradas à paisagem urbana de modo a servir também como um espaço de recreação e lazer; na terceira fase, soma-se mais uma função que é a de contribuir para a melhoria da qualidade do escoamento superficial; entretanto, na quarta fase, os esforços são concentrados em estudar a viabilidade de se usar esse volume de água armazenado como eventual fonte de abastecimento.

Diante do exposto, o presente estudo apresenta os resultados obtidos do monitoramento de duas bacias de detenção, uma alagada (que se comporta também como bacia de retenção) e 
uma seca, situadas na cidade de Brasília - DF, tendo como objetivo, avaliar a eficiência delas no amortecimento do pico das cheias e, ainda, observar os seus comportamentos no que diz respeito à remoção da concentração de poluentes trazidos pelo escoamento superficial e a possível contaminação das águas pluviais por esgoto doméstico.

A motivação implícita neste estudo é a verificação da viabilidade, ou não, no contexto da cidade de Brasília, da possibilidade de implementar medidas compensatórias para o controle do escoamento pluvial urbano e que também atendam a outras finalidades.

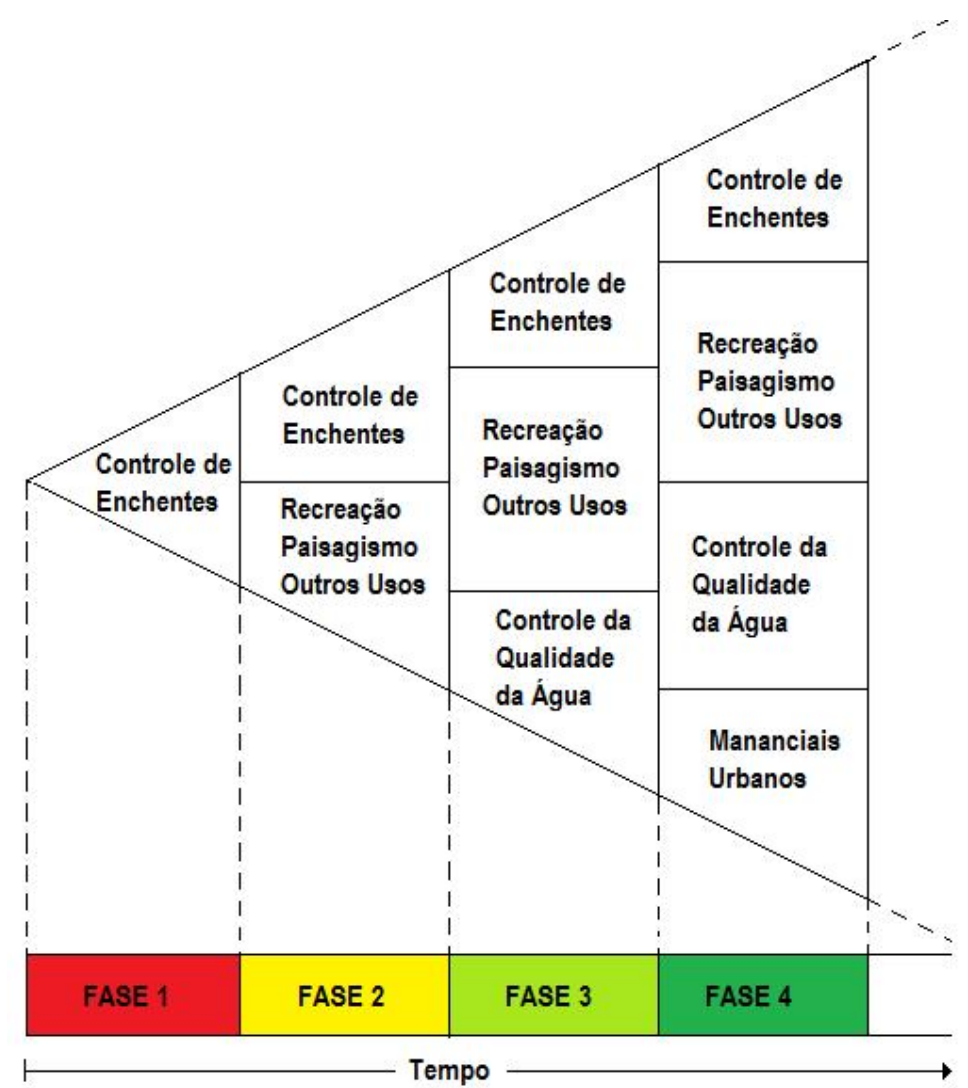

Figura 1. Evolução da utilização de estruturas de detenção em áreas urbanas

\section{MATERIAL E MÉTODOS}

As bacias de detenção monitoradas se encontram localizadas no Plano Piloto da cidade de Brasília - DF, conforme ilustrado na Figura 2, e recebem os escoamentos provenientes de zonas residenciais, comerciais e de vias expressas.

Quanto ao clima, no Distrito Federal predomina o quente e semi-úmido. Segundo a classificação de Köppen, o clima dominante no Distrito Federal é o tropical (Aw) e o tropical de altitude (Cwa) e (Cwb). Existem duas estações bem definidas, uma chuvosa e quente que ocorre entre os meses de outubro e abril, e outra fria e seca que ocorre entre maio e setembro. Os meses mais chuvosos são os de novembro a janeiro. Com relação aos índices de precipitação, a média pluviométrica anual fica em torno de 1500 a $1700 \mathrm{~mm}$. Já a média térmica anual varia entre 22 a $24^{\circ} \mathrm{C}$, a média máxima ultrapassa $25^{\circ} \mathrm{C}$ e a média mínima alcança $18^{\circ} \mathrm{C}$ (Gomes, 2004).

Essas bacias têm as características descritas a seguir: 


\subsection{Bacia de Detenção “Alagada”}

A bacia de detenção monitorada encontra-se localizada no Parque da Cidade de BrasíliaBrasil e é uma bacia permanentemente alagada, que além do controle de inundações é elemento urbanístico do referido parque, bastante freqüentado pela comunidade da cidade. Essa bacia recebe o escoamento de uma área de drenagem de $6,12 \mathrm{~km}^{2}$, sendo $0,11 \mathrm{~km}^{2}$ de área comercial, 2,28 $\mathrm{km}^{2}$ de área residencial, $3,28 \mathrm{~km}^{2}$ de área sem ocupação (gramada, em parque ou cerrado) e $0,45 \mathrm{~km}^{2}$ ocupado pelo sistema viário, incluindo calçadas e passeios, e apresenta as seguintes características: área de $0,167 \mathrm{~km}^{2}$, profundidade média de $0,68 \mathrm{~m}$, comprimento no sentido longitudinal predominante do escoamento de $809 \mathrm{~m}$.

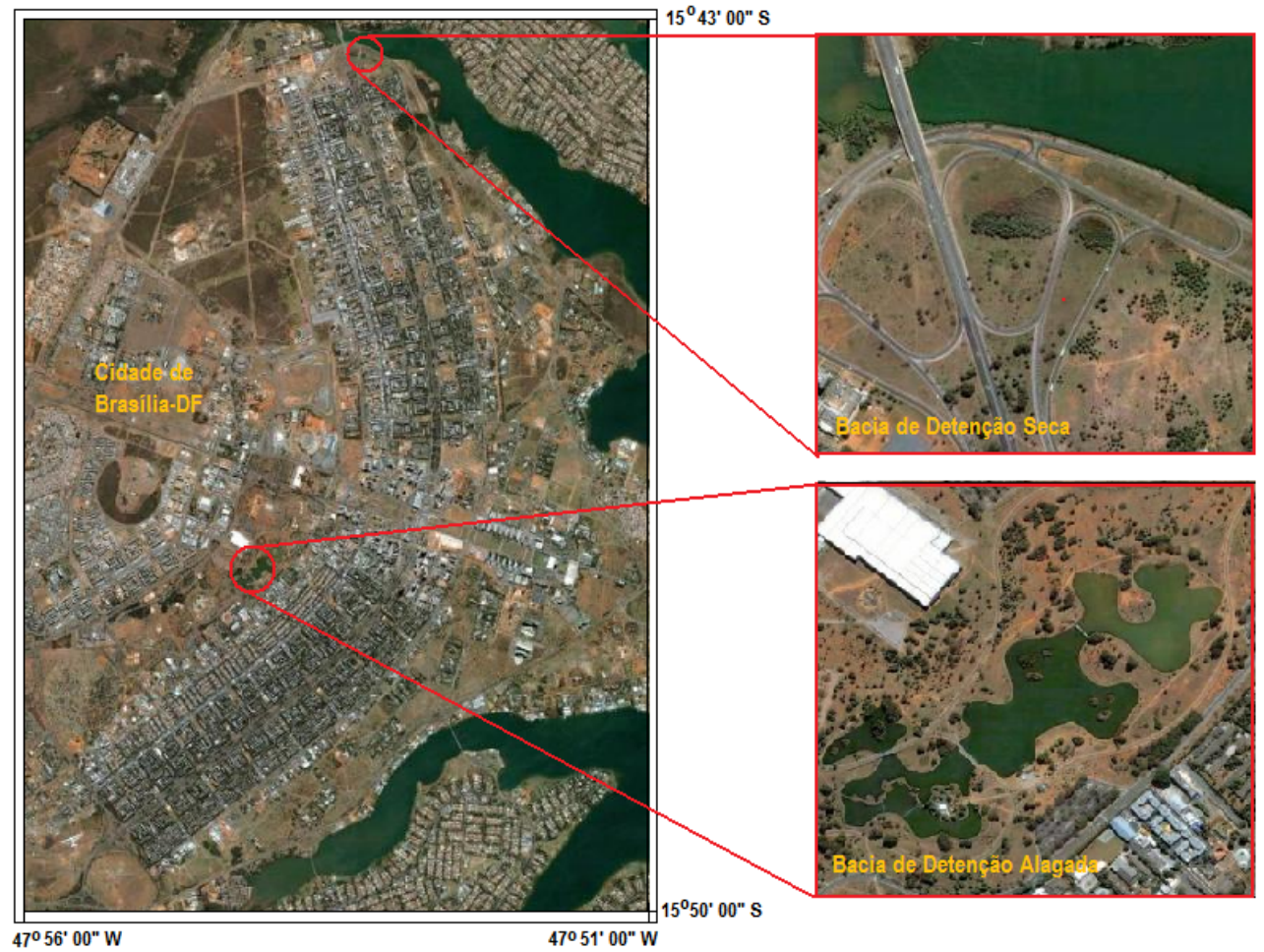

Figura 2. Localização das bacias de retenção monitoradas (imagem Spot 5 de 17/07/2005).

\subsection{Bacia de Detenção “Seca”}

Esta bacia de detenção está localizada no final do bairro Asa Norte, é uma bacia de detenção seca, menor que a bacia de detenção alagada e recebe o escoamento proveniente de uma área de contribuição de $4,75 \mathrm{~km}^{2}$, sendo $0,64 \mathrm{~km}^{2}$ utilizado pelo comércio local, $1,05 \mathrm{~km}^{2}$ de área residencial composta por edifícios, $2,68 \mathrm{~km}^{2}$ de área sem ocupação destinada à área gramada, parque e cerrado e $0,38 \mathrm{~km}^{2}$ ocupada pelo sistema viário incluindo calçadas e passeios, e possui as seguintes características: área de $0,024 \mathrm{~km}^{2}$, profundidade média de 0,52m, comprimento da direção predominante do escoamento de $63 \mathrm{~m}$.

Para o presente estudo foram coletados dados de vazão (hidrograma de escoamento superficial) e qualidade da água nas canalizações de entrada da bacia de detenção, aqui denominadas de seção de montante, e nas canalizações de saída da bacia de detenção, aqui denominadas de seção de jusante.

\subsection{Monitoramento Quantitativo}

A estratégia de monitoramento das bacias de detenção foi elaborada com base nas propostas apresentadas por EPA (1986), e Guo e Urbonas (2002). Basicamente, consistiu da determinação da vazão de montante e a de jusante das bacias de detenção feita utilizando-se 
um vertedor triangular e régua linimétrica. Em cada um dos eventos monitorados foram realizadas medições de vazão em intervalos de cinco minutos ao longo de períodos que variaram de quatro a cinco horas para a maioria dos eventos, mas para um dos eventos monitorados o período total de medição foi de sete horas e meia.

O comportamento da bacia de detenção seca foi monitorado para três eventos chuvosos, enquanto o monitoramento do comportamento da bacia de detenção alagada se deu para outros dois eventos chuvosos. Nesta última bacia foi, também, medido o hidrograma de entrada durante um dia no qual não houve ocorrência de precipitação, com o intuito de verificar a existência de ligações clandestinas de esgoto na rede de drenagem.

O período de monitoramento de ambas as bacias foi de 14/12/2004 até 21/2/2005. Os motivos pelos quais a quantidade de eventos monitorados foi muita reduzida são: após monitorar o segundo evento na bacia alagada, os equipamentos de medição de vazão (vertedor e régua linimétrica) foram depredados; b) a bacia seca possuía apenas uma entrada, mas após monitorar o terceiro evento, sua estrutura foi modificada, incorporando-se mais entradas o que impossibilitou a continuidade do monitoramento em função da reduzida quantidade de equipamento disponível para esta finalidade.

\subsection{Monitoramento Qualitativo}

A concepção do monitoramento da qualidade do escoamento baseou-se nas sugestões de EPA (1986), Gray e Becker (2002), Lee e Bang (2000) e Lee et al. (2002), que recomendam tomar cuidado para que os parâmetros escolhidos para análise de amostras do escoamento envolvam a análise de, no mínimo, matéria orgânica, nutrientes, microbiologia e metais pesados. A escolha dos parâmetros para o presente trabalho foi baseada nesse princípio, além de levar em conta também os parâmetros mais usuais.

As características físicas do efluente foram analisadas por meio da medida da temperatura e sólidos em suspensão. As características químicas foram analisadas por meio do $\mathrm{pH}$, condutividade (quantidade de sais) e metais pesados. Os nutrientes foram avaliados por meio do orto-fosfato e nitrato. Os parâmetros utilizados para análise de matéria orgânica contida na água foram DBO, DQO e óleos e graxas. Já as características microbiológicas foram analisadas por meio da medida de coliformes totais e termotolerantes.

A metodologia utilizada para análise de cada parâmetro, de acordo com o Standard Methods (APHA; AWWA; WPCF, 2005) é apresentada na Tabela 2.

Tabela 2. Métodos utilizados para análise dos parâmetros de qualidade da água.

\begin{tabular}{ll}
\hline Parâmetro & Método Utilizado \\
\hline Temperatura & Termômetro \\
pH & Phmetro \\
Condutividade elétrica & Condutivímetro \\
DBO & Respirométrico \\
DQO & Colorimétrico de refluxo fechado \\
Orto-fosfato & Colorimétrico do ácido ascórbico \\
Nitrato & Colorimétrico \\
Coliformes & Colilert \\
Sólidos em suspensão & Gravimétrico \\
Óleos e graxas & Gravimétrico
\end{tabular}

Foram coletadas amostras do escoamento pluvial a montante e a jusante da bacia de detenção, ao longo dos eventos chuvosos para caracterizar e avaliar a contribuição dessas bacias na melhora da qualidade da água da drenagem pluvial. 
Em função de ter sido observado no escoamento de entrada da bacia de detenção alagada que, em determinados horários, havia uma concentração maior de substâncias características de esgotos domésticos, suspeitou-se da existência de conexões clandestinas de esgoto na rede de drenagem pluvial. Sendo assim, foi feita uma campanha para determinação da vazão e das respectivas concentrações de poluentes na água da rede de drenagem em um dia sem chuva.

\section{RESULTADOS E DISCUSSÃO}

As Figuras de 3 a 5 correspondem aos hidrogramas de escoamento superficial registrados na bacia de detenção seca; entretanto as Figuras 6 e 7 mostram os hidrogramas medidos na bacia de detenção alagada. Esses resultados mostram claramente a eficiência hidráulica das bacias de detenção no que diz respeito à redução das vazões de pico das ondas de cheia, principalmente da bacia de detenção alagada que pelo seu maior tamanho apresenta, conseqüentemente, uma maior capacidade de amortecimento das vazões.

A Tabela 3 apresenta os valores das vazões de pico medidas na seção de montante e na seção de jusante para os eventos com chuva das bacias de detenção monitoradas; o tempo ao pico para cada caso; a porcentagem de redução observada na vazão de pico; a precipitação observada; assim como a precipitação antecedente (precipitação total acumulada ocorrida nos cinco dias anteriores ao evento monitorado).

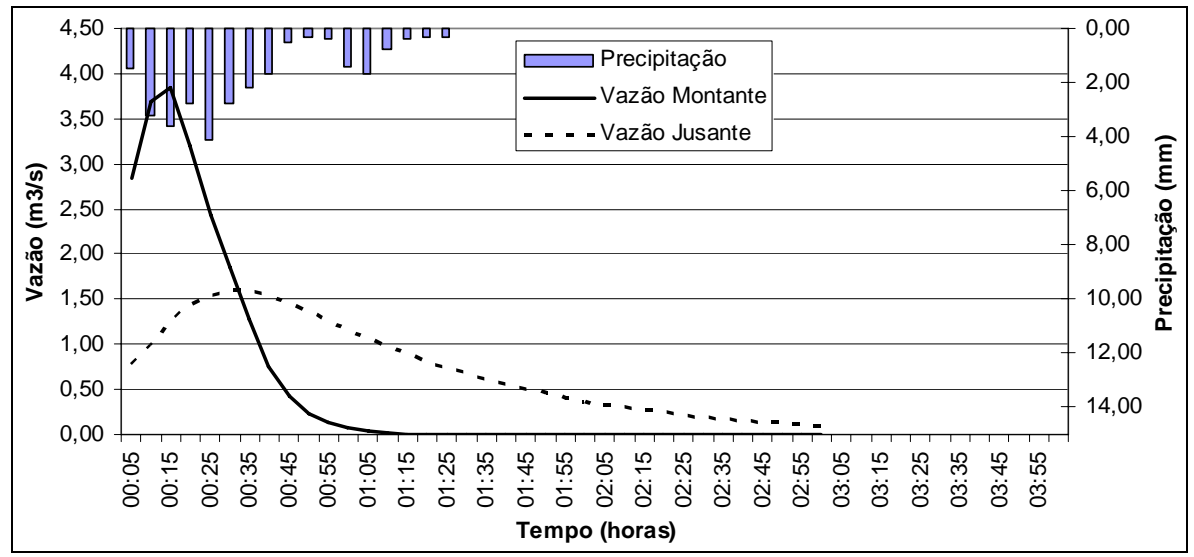

Figura 3. Hidrogramas nas seções de montante e jusante na bacia de detenção seca - Evento 1.

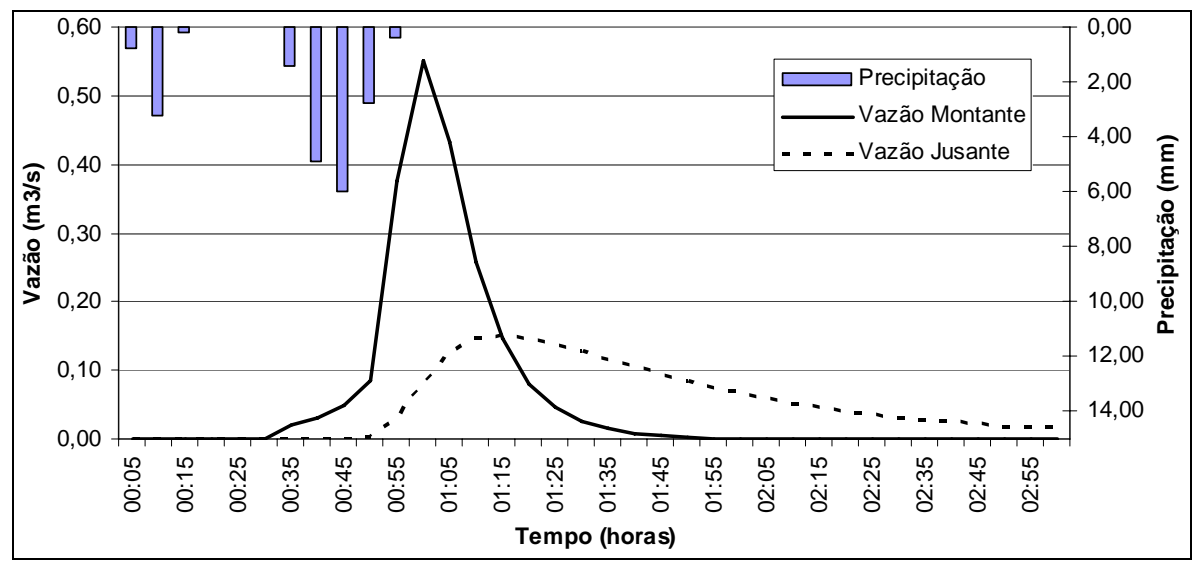

Figura 4. Hidrogramas nas seções de montante e jusante na bacia de detenção seca - Evento 2. 


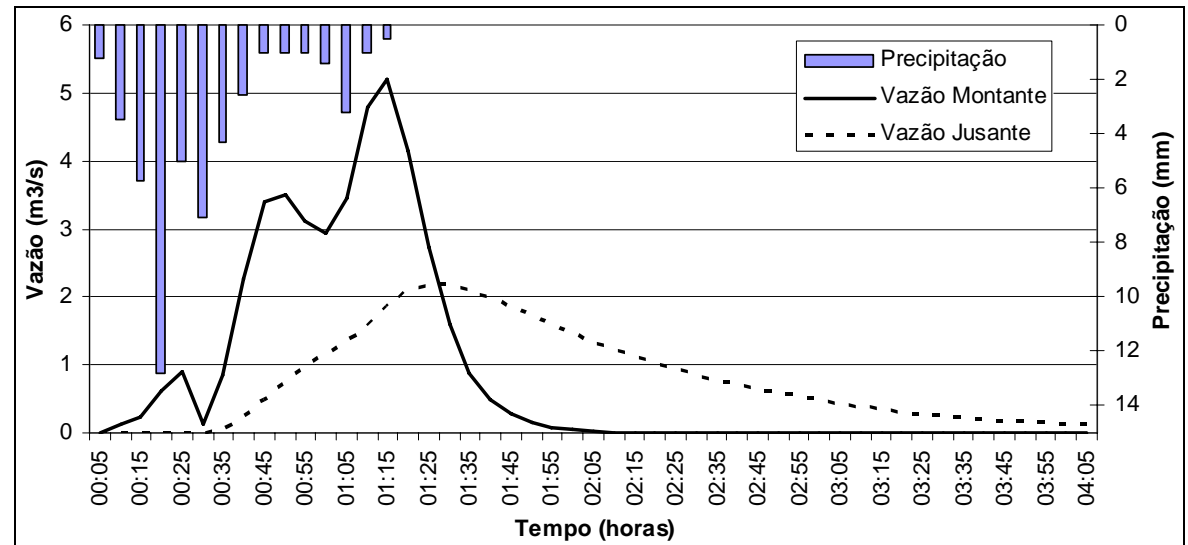

Figura 5. Hidrogramas nas seções de montante e jusante na bacia de detenção seca - Evento 3.

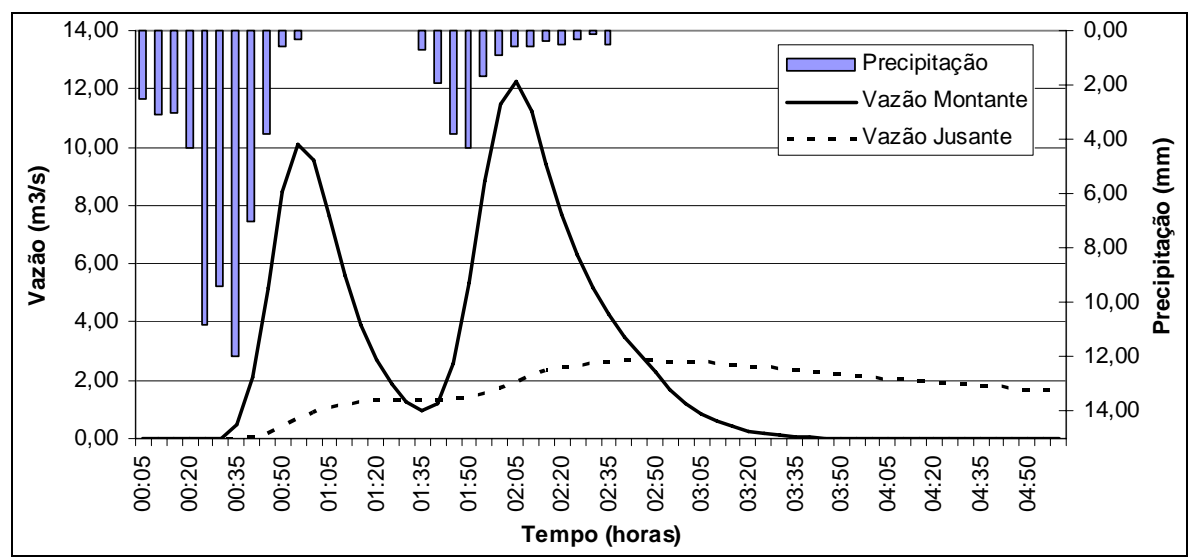

Figura 6. Hidrogramas nas seções de montante e jusante na bacia de detenção alagada - Evento 1.

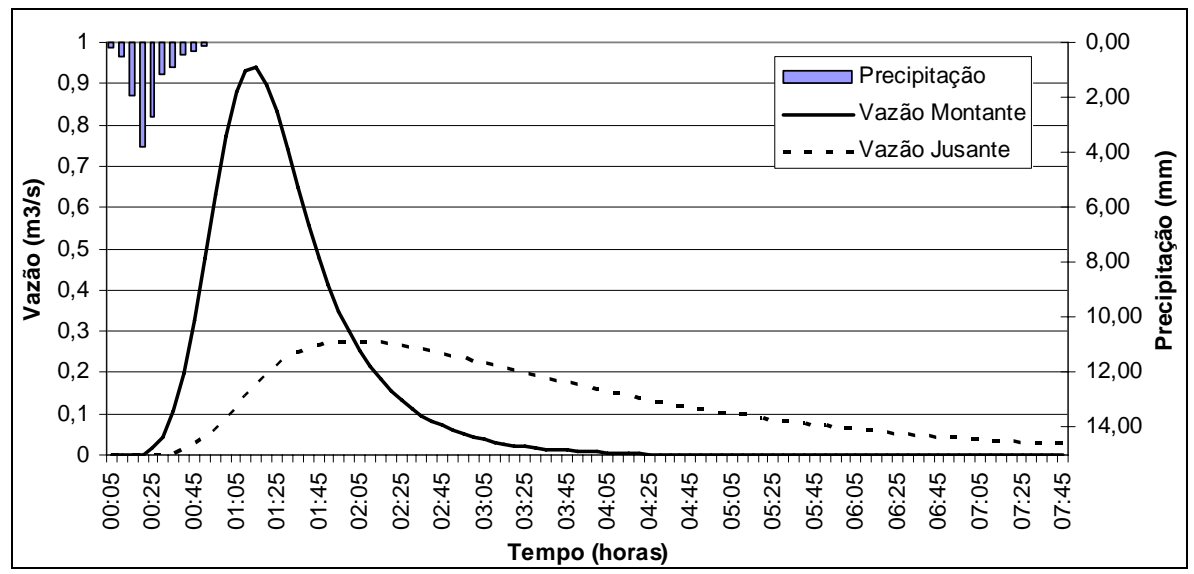

Figura 7. Hidrogramas nas seções de montante e jusante na bacia de detenção alagada - Evento 2.

Assim como observado nas Figuras 3 a 7, os dados da Tabela 3 vêm comprovar a eficiência hidráulica de bacias de detenção tanto seca quanto inundada como mecanismo para o controle de cheias em áreas urbanas, uma vez que a redução média observada na vazão de pico foi de $62,6 \%$ e $74 \%$, para a bacia de detenção seca e alagada, respectivamente. Além da alta taxa de redução das vazões de pico observadas para a bacia de detenção alagada, pode-se ainda observar o aumento significativo no tempo ao pico para esta bacia. O mesmo não 
ocorreu para a bacia de detenção seca porque ela possui dimensões reduzidas em relação à bacia de detenção inundada.

Tabela 3. Valores das vazões de pico para os eventos monitorados a montante e a jusante e porcentagem de redução da vazão de pico.

\begin{tabular}{|c|c|c|c|c|c|c|c|c|}
\hline $\begin{array}{l}\text { Bacia de } \\
\text { detenção }\end{array}$ & Evento & $\begin{array}{c}\text { Vazão de } \\
\text { pico de } \\
\text { montante } \\
\left(\mathbf{m}^{3} / \mathbf{s}\right)\end{array}$ & $\begin{array}{l}\text { Tempo ao } \\
\text { pico de } \\
\text { montante } \\
\text { (h) }\end{array}$ & $\begin{array}{c}\text { Vazão de } \\
\text { pico de } \\
\text { jusante } \\
\left(\mathbf{m}^{3} / \mathbf{s}\right)\end{array}$ & $\begin{array}{l}\text { Tempo ao } \\
\text { pico de } \\
\text { jusante } \\
\text { (h) }\end{array}$ & $\begin{array}{c}\text { Redução } \\
\text { da vazão } \\
\text { de pico } \\
(\%)\end{array}$ & $\begin{array}{c}\text { Precipitação } \\
\text { (mm) }\end{array}$ & $\begin{array}{c}\text { Precipitação } \\
\text { antecedente } \\
(\mathbf{m m})\end{array}$ \\
\hline \multirow{3}{*}{ Seca } & 1 & 3,84 & $01: 55$ & 1,6 & 01:30 & 58 & 28,0 & 5,3 \\
\hline & 2 & 0,55 & 01:00 & 0,15 & 01:10 & 72 & 19,7 & 0,0 \\
\hline & 3 & 5,2 & $01: 15$ & 2,19 & $01: 25$ & 58 & 51,3 & 0,0 \\
\hline \multirow{3}{*}{ Alagada } & \multirow[t]{2}{*}{1} & 10,08 & $00: 55$ & \multirow{2}{*}{2,69} & \multirow{2}{*}{ 02:45 } & 73 & \multirow{2}{*}{73,1} & \multirow{2}{*}{12,8} \\
\hline & & 12,26 & 02:05 & & & 78 & & \\
\hline & 2 & 0,94 & 01:15 & 0,276 & 01:55 & 71 & 12,04 & 7,6 \\
\hline
\end{tabular}

No que se refere ao aspecto qualitativo do escoamento pluvial, as concentrações médias dos diversos parâmetros monitorados são apresentadas nas Tabelas 4 e 5, enquanto os valores da Tabela 6 referem-se à taxa média de redução da concentração de poluentes registrada na bacia de detenção.

A concentração média de cada parâmetro para cada evento chuvoso monitorado foi estimada da seguinte forma:

$$
C M E=\frac{\sum_{i=1}^{n} C_{i} \cdot Q_{i}}{\sum_{i=1}^{n} Q_{i}}
$$

Em que: $C M E$ é a concentração média do evento; $C_{i}$ é a concentração de cada amostra; $Q_{i}$ é a vazão do escoamento superficial no momento da coleta da amostra; e $n$ é a quantidade de amostras coletadas

Tabela 4. Concentração média dos parâmetros da qualidade do escoamento pluvial para a bacia de detenção seca.

\begin{tabular}{|c|c|c|c|c|c|c|c|c|c|c|c|}
\hline Evento & $\begin{array}{c}\text { Temp } \\
\left({ }^{\circ} \mathrm{C}\right)\end{array}$ & pH & $\begin{array}{l}\text { Condut. } \\
(\mu S / \mathbf{c m})\end{array}$ & $\begin{array}{c}\text { DQO } \\
(\mathrm{mg} / \mathrm{l})\end{array}$ & \begin{tabular}{|c|} 
DBO \\
(mg/l)
\end{tabular} & $\begin{array}{c}\text { Sol. } \\
\text { Suspen. } \\
\text { (mg/l) }\end{array}$ & $\begin{array}{c}\text { Nitrat } \\
\text { o } \\
(\mathrm{mg} / \mathrm{l})\end{array}$ & $\begin{array}{c}\text { Colif. } \\
\text { Totais } \\
(\mathrm{NMP} / \mathbf{1 0 0 m l})\end{array}$ & $\begin{array}{c}\text { Colif. } \\
\text { Termotoler } \\
\text { (NMP/100ml) }\end{array}$ & $\begin{array}{c}\text { Orto- } \\
\text { Fosfato } \\
\text { (mg/l) }\end{array}$ & $\begin{array}{c}\text { Óleos e graxas } \\
\text { (mg/l) }\end{array}$ \\
\hline \multicolumn{12}{|c|}{ Dados de Montante (seção de entrada) } \\
\hline 1 & 22,1 & 7,0 & 30,71 & 12,20 & 3,30 & 17,37 & 0,43 & 316800 & 21180 & 0,070 & 4,058 \\
\hline 2 & 19,2 & 6,5 & 29,19 & 15,19 & 1,29 & 12,15 & 0,35 & 327000 & 17425 & 0,071 & 11,270 \\
\hline 3 & 0,0 & 6,8 & 23,60 & 13,10 & 2,95 & 20,81 & 0,69 & 361023 & 20299 & 0,000 & 8,252 \\
\hline \multicolumn{12}{|c|}{ Dados de Jusante (seção de saída) } \\
\hline 1 & n.d. & 4,4 & n.d. & 11,66 & 3,20 & 8,97 & 0,39 & 299220 & n.d. & 0,065 & 3,380 \\
\hline 2 & n.d. & 7,3 & n.d. & 14,44 & 2,09 & 7,16 & 0,32 & 300840 & n.d. & 0,062 & 9,580 \\
\hline 3 & n.d. & 6,9 & n.d. & 12,65 & 2,77 & 10,63 & 0,60 & 326502 & n.d. & 0,000 & 7,664 \\
\hline
\end{tabular}

n.d.: informação não disponível. 
Tabela 5. Concentração média dos parâmetros da qualidade do escoamento pluvial para a bacia de detenção alagada.

\begin{tabular}{|c|c|c|c|c|c|c|c|c|c|c|c|}
\hline Evento & $\begin{array}{c}\text { Temp } \\
\left({ }^{\circ} \mathrm{C}\right)\end{array}$ & $\mathbf{p H}$ & $\begin{array}{l}\text { Condut. } \\
(\mu \mathrm{S} / \mathrm{cm})\end{array}$ & $\begin{array}{c}\text { DQO } \\
\text { (mg/l) }\end{array}$ & $\begin{array}{c}\text { DBO } \\
(\mathrm{mg} / \mathrm{l})\end{array}$ & $\begin{array}{c}\text { Sol. } \\
\text { Suspen. } \\
\text { (mg/l) }\end{array}$ & $\begin{array}{c}\text { Nitrato } \\
\text { (mg/l) }\end{array}$ & $\begin{array}{c}\text { Colif. } \\
\text { Totais } \\
(\mathrm{NMP} / 100 \mathrm{ml}) \\
\end{array}$ & \begin{tabular}{|c|} 
Colif. \\
Termotoler \\
(NMP/100ml)
\end{tabular} & $\begin{array}{c}\text { Orto- } \\
\text { Fosfato } \\
\text { (mg/l) }\end{array}$ & $\begin{array}{l}\text { Óleos e } \\
\text { graxas } \\
\text { (mg/l) } \\
\end{array}$ \\
\hline \multicolumn{12}{|c|}{ Dados de Montante (seção de entrada) } \\
\hline 1 & n.d. & 6,79 & & 74,50 & 9,25 & 95,00 & 1,10 & 536000 & 52033 & 0,168 & 12,650 \\
\hline 2 & n.d. & 6,59 & 53,16 & 36,05 & 9,17 & 95,05 & 1,15 & 1655608 & 89307 & 0,141 & 14,135 \\
\hline \multicolumn{12}{|c|}{ Dados de Jusante (seção de saída) } \\
\hline 1 & n.d. & 7,43 & n.d. & 67,32 & 8,44 & 43,40 & 0,81 & 477150 & n.d. & n.d. & 12,860 \\
\hline 2 & n.d. & 7,16 & n.d. & 33,24 & 8,65 & 37,83 & 1,03 & 1403493 & n.d. & n.d. & 11,515 \\
\hline
\end{tabular}

n.d.: informação não disponível.

Vale ressaltar a dificuldade de se conhecer com exatidão a qualidade das águas do escoamento pluvial urbano em função da existência de conexões clandestinas de esgoto na rede de drenagem, fato este comprovado com o monitoramento da bacia de detenção alagada em um dia (17/01/2005) sem ocorrência de chuva. O hidrograma observado nesse dia é mostrado na figura 8, enquanto na tabela 7, apresentam-se os dados de qualidade desse esgoto.

Tabela 6. Porcentagem de redução da concentração de poluentes para as bacias de detenção monitoradas.

\begin{tabular}{|l|c|c|}
\hline \multicolumn{1}{|c|}{ Parâmetro } & $\begin{array}{c}\text { \% de redução da bacia de } \\
\text { detenção seca }\end{array}$ & $\begin{array}{c}\text { \% de redução na bacia de } \\
\text { detenção alagada }\end{array}$ \\
\hline DQO & $4-7$ & $7-10$ \\
\hline DBO & $1-3$ & $5-9$ \\
\hline Sólidos Suspensos & $38-54$ & $41-74$ \\
\hline Nitrato & $7-11$ & $7-14$ \\
\hline Coliformes totais & $5-9$ & $10-24$ \\
\hline Óleos e graxas & $14-21$ & $14-21$ \\
\hline
\end{tabular}

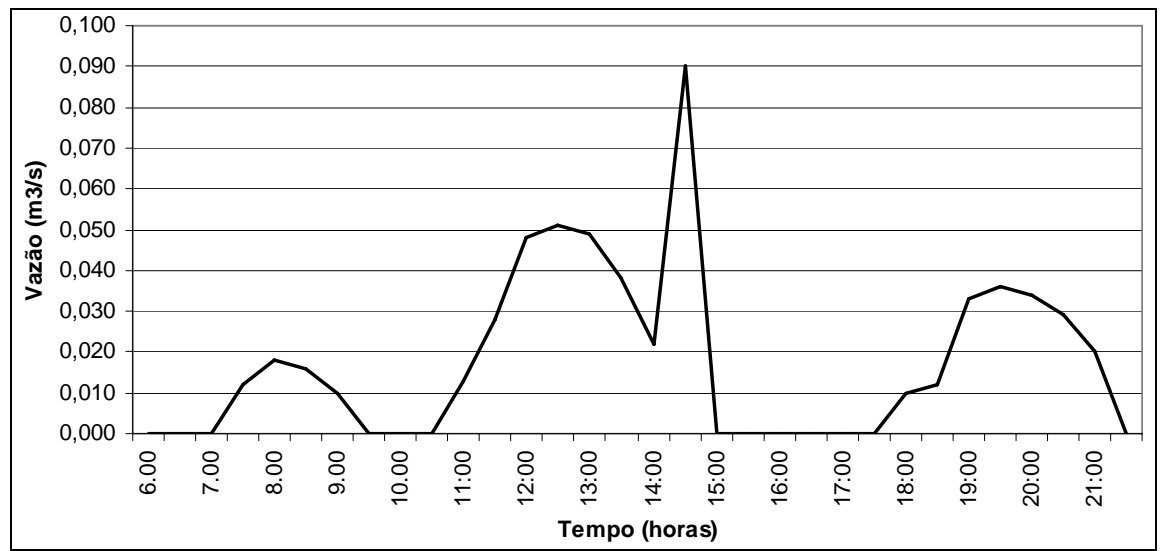

Figura 8. Hidrograma da seção de montante na bacia de detenção. Para um dia sem ocorrência de chuva. 
Tabela 7. Concentração média dos parâmetros da qualidade do escoamento pluvial para a bacia de detenção alagada.

\begin{tabular}{c|c|c|c|c|c|c|c|c}
\hline $\begin{array}{c}\text { Temp } \\
\left({ }^{\mathbf{O}} \mathbf{C}\right)\end{array}$ & $\mathbf{p H}$ & $\begin{array}{c}\text { Condut } \\
(\mathbf{\mu S / c m})\end{array}$ & $\begin{array}{c}\text { DQO } \\
(\mathbf{m g} / \mathbf{l})\end{array}$ & $\begin{array}{c}\text { DBO } \\
(\mathbf{m g} / \mathbf{l})\end{array}$ & $\begin{array}{c}\text { Sol. } \\
\text { Suspen. } \\
(\mathbf{m g} / \mathbf{l})\end{array}$ & $\begin{array}{c}\text { Nitrat } \\
\mathbf{o} \\
(\mathbf{m g} / \mathbf{l})\end{array}$ & $\begin{array}{c}\text { Colif. } \\
\text { Totais } \\
(\mathbf{N M P} / \mathbf{1 0 0 m l})\end{array}$ & $\begin{array}{c}\text { Colif. } \\
\text { Termotoler } \\
(\mathbf{N M P} / \mathbf{1 0 0 m})\end{array}$ \\
\hline 23 & 6,9 & 211,14 & 55,9 & 22,1 & 9,4 & 0,3 & 251.000 & 236.000 \\
\hline
\end{tabular}

Da observação dos dados apresentados na tabela 7, percebe-se que existe a possibilidade de que esse efluente seja proveniente tanto de ligações clandestinas de esgotos domésticos residenciais e comerciais quanto de ligações clandestinas de drenagem de jardins.

Há também a possibilidade de que esse escoamento se deva à própria infiltração da água. Essa conclusão é obtida devido aos baixos valores de DBO e DQO encontrados se comparados aos valores de esgotos brutos. A hipótese levantada quanto à presença de esgoto é devida, principalmente, à quantidade de coliformes termotolerantes e totais encontradas, embora não se saiba ao certo o valor de coliformes totais. Porém, percebe-se que o valor dos coliformes termotolerantes ficou um pouco abaixo do valor típico de esgoto bruto.

Contudo, a hipótese mais provável é que existam ligações clandestinas de esgoto bruto de residências e de comércios, porém esse esgoto pode estar sendo diluído pela presença de ligações clandestinas de drenagem de jardins e pela presença de águas subterrâneas.

Dado que os resultados evidenciaram a efetividade das bacias de detenção na melhoria da qualidade do escoamento pluvial urbano, o passo seguinte foi a determinação do coeficiente de remoção de poluente, pois este poderia ser usado como parâmetro de dimensionamento destas estruturas de detenção do escoamento.

Assim, considerando que a bacia alagada tem funcionamento como reator de fluxo disperso utilizaram-se os resultados das análises de qualidade da água para os eventos analisados para ajustar o modelo proposto por Metcalf e Eddy (1991), isto é, estimar o coeficiente de remoção de poluente:

$$
S=S_{0} \cdot \frac{4 \cdot a \cdot e^{1 / 2 \cdot d}}{(1+a)^{2} \cdot e^{a / 2 \cdot d}-(1-a)^{2} \cdot e^{-a / 2 \cdot d}}
$$

$d=\frac{D}{U \cdot L}=\frac{D \cdot t}{L^{2}}$

$a=\sqrt{1+4 \cdot K \cdot t \cdot d}$

Em que: $\mathrm{S}$ é a concentração do poluente efluente (massa $\cdot$ volume ${ }^{-1}$ ); $\mathrm{S}_{0}$ é a concentração do poluente afluente (massa $\cdot$ volume $^{-1}$ ); K é o coeficiente de remoção do poluente (tempo ${ }^{-1}$ ); $\mathrm{t}$ é o tempo de detenção (tempo); d é o número de dispersão (adimensional); D é o coeficiente de dispersão longitudinal (distância ${ }^{2} \cdot$ tempo $^{-1}$ ); U é a velocidade média na lagoa (distância • tempo $^{-1}$ ); e L é o comprimento do percurso longitudinal na lagoa (distância).

Chegou-se à conclusão de que é possível agrupar os poluentes em dois grandes grupos, considerando o coeficiente de remoção do poluente (K): a) Poluentes tipicamente em solução; e b) Poluente tipicamente em suspensão.

Aqueles com característica de material predominantemente em solução ou em partículas muito pequenas podem-se considerar representados pelos parâmetros DQO, DBO, nitrato, 
orto-fosfato e organismos coliformes. Para esse grupo de poluentes, os valores de $\mathrm{K}$ obtidos estão ao redor de $0,5 \mathrm{dia}^{-1}$.

Aqueles com características de material em suspensão, encontram-se os representados pelos parâmetros sólidos em suspensão e óleos e graxas. Nesses casos, os valores de K são superiores ao encontrado para os poluentes dissolvidos. Para o caso dos representados por sólidos em suspensão, os valores de $\mathrm{K}$ obtidos estão na ordem de 3,0 dia ${ }^{-1}$; no caso dos representados por óleos e graxas, os valores de $\mathrm{K}$ foram da ordem de $1,0 \mathrm{dia}^{-1}$.

A primeira grande conclusão é que a bacia remove, com maior eficiência, o grupo de poluentes com característica de material em suspensão. Essa característica está associada ao processo de remoção, que nesses sistemas funciona predominantemente como processo físico. Sobre a diferença entre aqueles caracterizados como sólidos suspensos e os óleos e graxas, a explicação pode ser dada pela característica do funcionamento hidráulico das bacias, onde o material flotante tem menor restrição para saída do que o material que sedimenta. Essas considerações podem levar a estudos sobre dispositivos de saída, procurando aumentar a eficiência do material flotante.

Comparando-se o desempenho das duas bacias, no tocante a remoção de poluentes, podese perceber que a bacia alagada tem desempenho um pouco superior à bacia seca. Isso pode ser explicado pelo fato de que a bacia alagada funciona semelhantemente a uma lagoa de estabilização, com desempenho ampliado pela razão de funcionar como um reator bioquímico.

Também, segundo Novotny (1991), pode-se considerar que a bacia seca funciona como reator de mistura completa, e assim tentou-se usar os resultados das análises de qualidade da água para os eventos analisados para ajustar o modelo proposto por Metcalf e Eddy (1991):

$$
S=\frac{S_{0}}{1+K \cdot t}
$$

Em que: S é a concentração do poluente efluente (massa $\cdot$ volume $^{-1}$ ); $\mathrm{S}_{0}$ é a concentração do poluente afluente (massa $\cdot$ volume $^{-1}$ ); $\mathrm{K}$ é o coeficiente de remoção do poluente (tempo ${ }^{-1}$ ); e t é o tempo de detenção (tempo).

Analogamente ao caso da bacia alagada, aqueles poluentes com característica de material predominantemente em solução ou em partículas muito pequenas podem-se considerar representados pelos parâmetros DQO, DBO, nitrato, orto-fosfato e organismos coliformes. Para esse grupo obteve-se um valor médio de $\mathrm{K}$ de $0,34 \mathrm{dia}^{-1}$. Para o caso dos poluentes representados por sólidos em suspensão, o valor médio de $\mathrm{K}$ foi $5,5 \mathrm{dia}^{-1}$; entretanto no caso dos poluentes representados por óleos e graxas, os valores de K estão na ordem de 1,1 dia $^{-1}$.

Da análise dos resultados, pode-se afirmar que a hipótese de ser possível encontrar um valor de K que funcione como parâmetro de dimensionamento parece viável. Entretanto, para que o modelo seja confirmado é necessário monitorar outras estruturas de retenção para ter mais segurança na estatística dos resultados.

\section{CONCLUSÕES}

Diante do exposto, pode-se concluir que a utilização de bacias de detenção como medida de controle de cheias apresenta resultados satisfatórios no aspecto quantitativo, podendo ainda colaborar para a redução da concentração dos poluentes oriundos dos diversos usos do solo em meio urbano que estejam em contato com as águas despejadas na rede de águas pluviais. 
Como era esperado, no presente estudo foi comprovada a existência, para a região do Distrito Federal, de um problema que aflige a maioria das cidades que adotam um sistema separador absoluto para esgoto: a contaminação das águas pluviais pela ligação clandestina de esgoto doméstico.

No tocante ao aspecto qualitativo das águas pluviais, a bacia de detenção alagada mostrou maior eficiência na retenção de poluentes, mas mesmo assim os valores apresentados ainda encontram-se muito aquém dos valores citados na literatura especializada, com exceção da remoção de sólidos em suspensão que apresentou uma taxa de remoção de 74\%.

Destaca-se aqui que os valores encontrados para o coeficiente de remoção do poluente (K) devem ser tomados com reservas, pois trata-se de uma primeira estimativa realizada com base num número reduzido de eventos observados. Contudo, há indícios claros da contribuição dessas estruturas na melhoria da qualidade do escoamento pluvial urbano.

\section{AGRADECIMENTOS}

Os autores agradecem a $\mathrm{CNPq}$ - Conselho Nacional de desenvolvimento Científico e Tecnológico, que financia o Projeto "Manejo de Águas Pluviais no Distrito Federal” no contexto do qual foi desenvolvida a presente pesquisa.

\section{REFERÊNCIAS}

AMERICAN PUBLIC HEALTH ASSOCIATION - APHA; American Water Works Association - AWWA; Water Environment Federation - WPCF. Standard methods for the examination of water and wasterwater. 16. ed. Washington: AWWA, 2005.

BAPTISTA, M.; NASCIMENTO, N.; BARRAUD, S. Técnicas compensatórias em drenagem urbana. Porto Alegre: ABRH, 2005. 266 p.

BERTONI, J. C. (org). Inundaciones urbanas en Argentina. Córdoba: Universitas, 2004. $254 \mathrm{p}$.

CAMPANA, N. A.; TUCCI, C. E. M. Predicting floods from urban development scenarios: case study of the Diluvio basin, Porto Alegre, Brazil. Urban Water, Oxford, v. 3, n. 2, p.113-124, 2001.

CANHOLI, A. P. Drenagem urbana e controle de enchentes. São Paulo: Oficina de Textos, 2005. 302 p.

CHOCAT, B.; ASHLEY, R.; MARSALEK, J.; MATOS, M. R.; RAUCH, W.; SCHILLING, W.; et al. Urban drainage - out-of-sight, out-of-mind? In: INTERNATIONAL CONFERENCE ON SUSTAINABLE TECHNIQUES AND STRATEGIES IN URBAN WATER MANAGEMENT, 5., June 6-10 2004, Lyon. Proceedings... Lyon: NOVATECH, 2004. p. 1659-1690.

ENVIRONMENTAL PROTECTION AGENCY - EPA. Methodology for analysis of detention basins for control of urban runoff quality. Washington: EPA, 1986. EPA440/5-87-001.

GOMES, V. M. Caracterização qualitativa e quantitativa da água de drenagem pluvial. 78f. 2004. Dissertação (Mestrado em Tecnologia Ambiental e Recursos Hídricos) Universidade de Brasília, Brasília, 2004. 
GRAY, S. R.; BECKER, N. S. C. Contaminant flows in urban residential water systems. Urban Water, v. 4, p.331-346, 2002.

GUO, JAMES C. Y.; URBONAS, B. Runoff capture and delivery curves for storm water quality control designs. ASCE Journal of Water Resources Planning and Management, v. 128, n. 3, p. 208-215. 2002.

JONES, J.; GUO, J. C. Y.; URBONAS, B. Safety on detention and retention pond designs. Journal of Storm Water, 2006.

LEE, J. H.; BANG, K. W. Characterization of urban stormwater runoff. Water Research, v. 34, n. 6, p. 1773-1780, 2000.

LEE, J. H.; BANG, K. W.; KETCHUM, L. H.; CHOE, J. S.; YU, M. J. First flush analysis of urban storm runoff. The Science of the Total Environment, v. 293, p. 163-175, 2002.

METCALF, J.; EDDY, H. Wastewater engineering: treatment, disposal and reuse. 3. ed. Singapure: McGraw-Hill, 1991. 334 p.

MAYS, L. W.; PE, P. H. Stormwater collection systems design handbook. [S.l.]: McGrawHill, 2001. 757 p.

NOVOTNY, V. Urban diffuse pollution: sources and abatement. Water Environment \& Technology, v. 3, n. 12, p.60-65, 1991.

PREFEITURA MUNICIPAL DE SÃO PAULO - PMSP. Diretrizes básicas para projetos de drenagem urbana no município de São Paulo. São Paulo: FCTH-USP, 1999. 289 p.

SILVA, G. B. L. Avaliação experimental da eficiência de superfícies permeáveis com vistas ao controle do escoamento superficial. 199f. 2006. Tese (Doutorado em Tecnologia Ambiental e Recursos Hídricos) - Universidade de Brasília, Brasília, 2006.

URBAN DRAINAGE AND FLOOD CONTROL DISTRICT. Urban storm drainage criteria manual. Denver: Urban Drainage and Flood Control District, 1991. 665 p. Vol. 3 - Best management practices.

WALESH, S. G. Urban surface water management. New York: John Wiley \& Sons, 1989. 599p. 